\title{
Os grupos de pesquisa em comunicação e esporte no Brasil: perfil, produção e focos de interesse
}

\author{
The research groups in communication and sports \\ in Brazil: profile, production and focuses of interest
}

\author{
Los grupos de investigación en comunicación \\ y deporte en Brasil: perfil, producción y \\ focos de interés
}

Wilson da Costa Bueno

- Doutor e mestre em Ciências da Comunicação pela Escola de Comunicações e Artes da Universidade de São Paulo (ECA-USP)

- Graduado em Comunicação Social - Jornalismo e especialista em Comunicação Rural pela ECA-USP

- Professor do Programa de Pós-Graduação em Comunicação Social da Universidade Metodista de São Paulo (Umesp)

- Editor de oito portais temáticos em Comunicação/Jornalismo

- Líder do grupo de pesquisa "Criticom - Comunicação empresarial no Brasil: uma leitura critica", cadastrado no CNPq

- Consultor em comunicação empresarial e jornalismo especializado

- Livros recentes publicados: Comunicação empresarial: políticas e estratégia;

Comunicação empresarial no Brasil: uma leitura critica; Comunicação, jornalismo e meio ambiente: teoria e pesquisa

- Áreas principais de atuação: comunicação empresarial e jornalismo especializado (jornalismo científico, ambiental, em saúde e em agribusiness)

-wilson@comtexto.com.br 
Resumo

O artigo identifica e descreve o perfil dos grupos de pesquisa em comunicação e esporte no Brasil registrados no Diretório dos Grupos de Pesquisa do Conselho Nacional de Desenvolvimento Científico e Tecnológico (CNPq) e levantados a partir de inúmeras palavras-chaves que caracterizam, sobretudo, a relação entre a mídia e o esporte. Analisam-se suas características, sua produção bibliográfica e seu vínculo com as áreas de conhecimento.

PALAVRAS-CHAVE: COMUNICAÇÃO E ESPORTE - MÍDIA E ESPORTE - MARKETING ESPORTIVO • JORNALISMO

ESPORTIVO • IMPRENSA ESPORTIVA • MÍDIA E FUTEBOL

Abstract

This article identifies and describes the profile of groups that research on communication and sport in Brazil, raised in the Directory of Research Groups of the National Council of Scientific and Technological Development (CNPq) from many keywords that mainly characterize the relation between the media and sports. It also analyses the features of these groups, their bibliographic production and their links with the areas of knowledge.

KEYWORDS: COMMUNICATION AND SPORT • MEDIA AND SPORT • SPORT MARKETING • SPORT PRESS • MEDIA AND SOCCER

Resumen

El artículo identifica y describe el perfil de los grupos de investigación en comunicación y deporte en Brasil, inscritos en el Directorio de Grupos de Investigación del Consejo Nacional de Desarrollo Científico y Tecnológico (CNPq) y descubiertos mediante el uso de innúmeras palabras clave que caracterizan, sobre todo, la relación entre los medios de comunicación y el deporte. Se analizan sus características, su producción bibliográfica y su vínculo con las áreas de conocimiento.

PALABRAS CLAVE: COMUNICACIÓN Y DEPORTE • MEDIOS DE COMUNICACIÓN Y DEPORTE • MARKETING DEPORTIVO • PERIODISMO DEPORTIVO • MEDIOS DE COMUNICACIÓN Y FÚTBOL 
A realização de megaeventos esportivos no Brasil, como a Copa do Mundo de Futebol e os Jogos Olímpicos, previstos, respectivamente, para 2014 e 2016, tem estimulado o debate sobre diversos aspectos relacionados com o esporte, notadamente em sua perspectiva política e econômica. De maneira surpreendente, é possível perceber que essa mobilização, ainda que esteja presente na agenda da mídia, não se tem feito acompanhar, na mesma proporção, pelo aumento expressivo da literatura sobre esporte no Brasil e, sobretudo, pela sua legitimação no âmbito da academia, com a realização de amplos projetos de investigação.

É provável que, à medida que as datas dos eventos se aproximem, as editoras comerciais programem lançamentos voltados para o esporte, porque esta tem sido a tônica em situações simulares, como, por exemplo, o aparecimento de novos títulos sobre meio ambiente, desenvolvimento sustentável ou ecologia de maneira geral por ocasião de grandes eventos nacionais e internacionais sobre esta temática. Como a produção acadêmica e científica requer, no entanto, tempo e depende da existência e da atuação sistemática de grupos constituídos de pesquisa, é essencial verificar se já dispomos dessas condições favoráveis, particularmente quando contemplamos a produção de pesquisa e estudos sobre as múltiplas relações entre comunicação e o esporte.

Nesse sentido, debruçamo-nos sobre o tema, buscando levantar, descrever e analisar os grupos de pesquisa focados em comunicação e esporte no Brasil.

Tradicionalmente, com exceção de alguns focos específicos, a bibliografia sobre comunicação e esporte no Brasil é pouco expressiva. Ela se concentra notadamente no campo da história, em especial do futebol, contemplando especialmente os clubes esportivos, os diversos campeonatos nacionais e regionais, a seleção brasileira e, em muitos casos, dando atenção especial à biografia dos seus ídolos. Há algumas centenas de trabalhos, alguns formidáveis em termos de resgate histórico, de maior ou menor fôlego, que enriquecem a literatura brasileira sobre a história do futebol.

Podem-se apontar, também, trabalhos que versam sobre a relação entre esporte, cultura e sociedade. É o caso de obras tradicionais como a de Georges Magnane, Sociologia do esporte (1969), que foca a atração exercida pelo esporte, a sua caracterização como atividade de lazer e mesmo a mitificação dos ídolos esportivos. Ou da emblemática O negro no futebol brasileiro, de Mário Rodrigues Filho, cuja primeira edição circulou em 1947 e que analisava, com notável lucidez, as relações entre futebol, racismo e identidade nacional. Da mesma forma, podem ser destacados estudiosos como Richard Giulianotti, com Sociologia do futebol (2002), que aborda a essência do futebol, suas bases históricas e sociais, as dimensões culturais do espectador, a questão financeira e do controle social e a importância dos heróis; Francisco Carlos Teixeira Silva e Ricardo Pinto Santos, com Memória social dos esportes (2006); Arlei Sander Damo, com Futebol e identidade social (2002), que privilegia a noção de pertencimento dos 
torcedores e o conceito de clube como nação. Merece menção também o trabalho organizado por Jocimar Daolio, Futebol, cultura e sociedade (2005), que reúne ensaios de vários pesquisadores vinculados à Faculdade de Educação Física da Universidade Estadual de Campinas (Unicamp) sobre temas de interesse nessa área, como a superstição no futebol, a construção social da paixão, a rivalidade entre torcedores, a questão da violência nos estádios etc.

Não se pode ignorar também a obra pioneira de E. Myra Y Lopes e Athayde Ribeiro da Silva, Futebol e psicologia (1964), publicado há quase cinquenta anos, e que enfatizava a importância da orientação psicológica nos esportes, incluía reflexões sobre a psicologia do torcedor e defendia o exame psicotécnico para jogadores e árbitros.

No que diz respeito a comunicação e esporte, a literatura nacional tem sido menos generosa, com algumas poucas dezenas de obras voltadas para depoimentos de jornalistas e comentaristas esportivos ou que se constituem em manuais sobre jornalismo esportivo, como é o caso dos textos de Heródoto Barbeiro e Patrícia Rangel (2006), Paulo Vinicius Coelho (2003), Celso Unzeltte (2009), entre outros. É de se registrar, sobretudo neste século, o lançamento de inúmeras obras sobre marketing esportivo, a maioria delas traduzidas de autores estrangeiros, como as de Irving Rein, Philip Kotler e Ben Schields (2008), Wesley Cardia (2004), Brenda Pitts e David K. Stotlar (2002), Melissa J. Morgan e Jane Summers (2008) ou mesmo o trabalho de Anderson Gurgel (2006) sobre futebol como negócio. É indispensável registrar o lançamento do Atlas do esporte no Brasil (2005), organizado por Lamartine da Costa, o qual representa um trabalho exaustivo, com a colaboração de uma centena de profissionais, estudiosos e pesquisadores, resgatando a história e o perfil das associações esportivas em dezenas de modalidades, incluindo propostas voltadas para a saúde, o lazer e a inclusão social visando a uma política nacional do esporte, além de artigos sobre marketing esportivo, memórias e museus do esporte e aspectos relacionados à realização de megaeventos como teremos no Brasil nos próximos anos.

Estudos e reflexões que focalizam a relação entre a comunicação e o esporte podem ser encontrados em duas obras patrocinadas pela Sociedade Brasileira de Estudos Interdisciplinares da Comunicação (Intercom), organizadas por José Carlos Marques (2007), assim como pelo mesmo autor junto com Sérgio Carvalho e Vera Regina Toledo Camargo (2005). Na prática, os congressos da Intercom, realizados anualmente, incluem contribuições de estudantes, professores e pesquisadores nacionais sobre o tema, fruto do esforço dos diversos coordenadores que há algum tempo mantêm vivo o grupo de trabalho sobre essa temática, despertando novas vocações. É digna ainda de menção a coletânea organizada por Sérgio Vilas Boas (2005), a qual, além de incorporar estudos sobre vários aspectos da comunicação e informação esportiva, teve a virtude de não se limitar ao universo do futebol, como tem sido comum em nosso país. 


\section{OS GRUPOS DE PESQUISA}

O mapeamento dos grupos de pesquisa em comunicação em esporte no Brasil foi realizado por meio de consulta ao Diretório dos Grupos de Pesquisa registrados no CNPq em agosto de 2011, a partir de seis palavras ou conceitos-chave: esporte e sociedade; jornalismo esportivo; marketing esportivo; comunicação e futebol; comunicação e esporte; e mídia e esporte.

O mencionado diretório, desenvolvido pelo $\mathrm{CNPq}$ há quase uma década, reúne, em uma base de dados, os grupos em atividade no país. Os que constam dessa base vinculam-se, conforme define o portal do diretório, "a universidades, instituições isoladas de ensino superior, institutos de pesquisa científica, institutos tecnológicos e laboratórios de pesquisa e desenvolvimento de empresas estatais ou ex-estatais"' , mas não se levam em conta aqueles que, eventualmente, podem estar localizados em empresas privadas.

O diretório traz informações básicas sobre os grupos de pesquisa, incluindo os seus recursos humanos (pesquisadores, estudantes e corpo técnico) com indicação explícita do(s) seu(s) líder(es), as linhas de pesquisa, sua produção científica ou tecnológica e seu vínculo com as instituições que os certificam, ano de criação, além da especialidade do conhecimento a que se filiam e informações gerais sobre os setores de aplicação envolvidos.

A seleção dos grupos de pesquisa em comunicação e esporte foi realizada em duas etapas. Num primeiro momento, a partir das seis palavras-chave escolhidas, identificaram-se os grupos de pesquisa recuperados pela busca no diretório do CNPq. A segunda etapa consistiu em selecionar, pelo levantamento parcial por palavras-chave: 1 ) apenas aqueles que tinham como foco prioritário efetivamente o tema comunicação e esporte, assumindo a comunicação em sua perspectiva prioritariamente midiática (o que sempre ocorria nos grupos que tinham explicitamente a comunicação como área de conhecimento predominante); 2 ou aqueles que incluíam comunicação e esporte como linha de pesquisa, ainda que a área do conhecimento predominante em que se inseria o grupo não fosse a comunicação. Como na busca por palavras-chaves alguns grupos apareciam repetidamente, buscou-se, ao final, incluí-los no levantamento uma única vez.

Numa primeira consulta, foram recuperados para as palavras-chaves citadas, 102 grupos de pesquisa, mas, como alguns grupos são resgatados por mais de uma palavra-chave, excluímos as duplicações e chegamos a um total de 82 grupos de pesquisa. Na prática, esse total apenas representa o número de grupos de pesquisa que se podem levantar, no Diretório de Grupos de Pesquisa do $\mathrm{CNPq}$, com o uso das palavras-chave definidas - esporte e sociedade; jornalismo esportivo; marketing esportivo; comunicação e futebol; comunicação e esporte; e mídia e esporte.

$1<$ http://dgp.cnpq.br/buscaoperacional/>. 
PERFIL E FOCOS DE INTERESSE DOS GRUPOS

Área de conhecimento predominante

Os 82 grupos de pesquisa podem ser classificados segundo a área de conhecimento predominante, como indica a tabela 1 :

Tabela 1

Grupos de pesquisa:

total por área de conhecimento predominante

\begin{tabular}{|l|c|c|}
\hline \multicolumn{1}{|c|}{ Especialidade } & Número de grupos de pesquisa & $\%$ \\
\hline Administração & 2 & 2,44 \\
\hline Arquitetura e urbanismo & 1 & 1,22 \\
\hline Antropologia & 2 & 2,44 \\
\hline Comunicação & 6 & 7,32 \\
\hline Educação & 8 & 9,76 \\
\hline Educação física & 52 & 63,41 \\
\hline Engenharia de produção & 1 & 1,22 \\
\hline História & 5 & 6,09 \\
\hline Nutrição & 1 & 1,22 \\
\hline Psicologia & 1 & 1,22 \\
\hline Sociologia & 2 & 2,44 \\
\hline Turismo & 1 & 1,22 \\
\hline TOTAL & 82 & 100,00 \\
\hline
\end{tabular}

É fácil verificar, neste levantamento, que a educação física predomina como área de conhecimento predominante, responsável pelo maior número de grupos de pesquisa em comunicação e esporte, com $63,41 \%$ do total, seguida pela de educação $(9,76)$ e comunicação $(7,32 \%)$, nesta ordem.

A maioria absoluta dos grupos de pesquisa, porém, não tem efetivamente foco em comunicação, ou seja, apesar de serem resgatados no sistema de busca do Diretório de Grupos de Pesquisa por palavras-chaves identificadas com a comunicação (jornalismo esporte, mídia e esporte, comunicação e futebol etc), preocupam-se com outros objetos de pesquisa (sociologia do esporte, educação física e esporte etc.). Como o interesse específico da pesquisa era levantar, 
descrever e analisar os grupos de específicos que têm a relação comunicação-esporte como objeto principal, excluímos os que não atendiam a esse critério. Com isso, o número de grupos de pesquisa inicial (82) reduziu-se drasticamente, limitando-se a apenas doze, com destaque àqueles que tinham como áreas de conhecimento predominantes a comunicação (como era de se esperar) e a educação física. Esses grupos de pesquisa é que foram objeto da nossa atenção e análise, compondo a distribuição por foco ou linha de pesquisa em comunicação que se mostra na tabela 2 .

Tabela 2

Grupos de pesquisa

com foco ou linha de pesquisa em comunicação e esporte

\begin{tabular}{|l|c|c|}
\hline \multicolumn{1}{|c|}{ Área de conhecimento predominante } & Número de grupos de pesquisa & $\%$ \\
\hline Antropologia & 1 & 8,33 \\
\hline Comunicação & 6 & 50,00 \\
\hline Educação física & 5 & 41,67 \\
\hline TOTAL & 12 & 100,00 \\
\hline
\end{tabular}

Distribuição dos grupos por estado, instituição e ano de formação

Os grupos de pesquisa se concentram em apenas sete estados brasileiros, como indica a tabela 3:

Tabela 3

Grupos de pesquisa em comunicação e esporte: distribuição por estado

\begin{tabular}{|l|c|c|}
\hline \multicolumn{1}{|c|}{ Estado } & Número de grupos de pesquisa & $\%$ \\
\hline Bahia & 2 & 16,67 \\
\hline Espírito Santo & 1 & 8,33 \\
\hline Goiás & 1 & 8,33 \\
\hline Rio de Janeiro & 2 & 16,67 \\
\hline Rio Grande do Sul & 2 & 16,67 \\
\hline Santa Catarina & 1 & 8,33 \\
\hline São Paulo & 3 & 25,00 \\
\hline TOTAL & 12 & 100,00 \\
\hline
\end{tabular}


Observa-se que $75 \%$ dos grupos de pesquisa estão situados no Sul e no Sudeste, vindo a seguir o Nordeste e o Centro-Oeste. Não há qualquer grupo de pesquisa no Norte brasileiro, que apresente como foco ou linha de pesquisa comunicação e esporte, cadastrado no $\mathrm{CNPq}$, com o perfil selecionado para esta análise.

Os grupos de pesquisa estão distribuídos por dez universidades e um centro universitário, sendo que apenas dois deles em uma mesma instituição (Universidade Federal de Santa Maria, mas em unidades diferentes - Departamento de Desportos Coletivos; e Laboratório de Pesquisa e Ensino do Movimento Humano). As universidades que abrigam grupos de pesquisa em comunicação e esporte, com foco ou linha de pesquisa em comunicação são, por estado, conforme tabela 4:

Tabela 4

Grupos de pesquisa em comunicação e esporte: distribuição por estado e instituição de pesquisa

\begin{tabular}{|l|l|c|}
\hline \multicolumn{1}{|c|}{ Estado } & \multicolumn{1}{|c|}{ Instituição } & $\begin{array}{c}\text { Número de grupos } \\
\text { de pesquisa }\end{array}$ \\
\hline \multirow{2}{*}{ Bahia } & Universidade Estadual de Santa Cruz (Uesc) & 1 \\
\cline { 2 - 4 } & Universidade de Salvador (Unifacs) & 1 \\
\hline \multirow{2}{*}{ Espírito Santo } & Universidade Federal do Espírito Santo (Ufes) & 1 \\
\hline Goiás & Universidade Federal de Goiás (UFG) & 1 \\
\hline \multirow{2}{*}{ Rio de Janeiro } & Universidade Federal Fluminense (UFF) & 1 \\
\hline \multirow{2}{*}{ Rio Grande do Sul } & Universidade do Estado do Rio de Janeiro (Uer) & 1 \\
\hline Santa Catarina & Universidade Federal de Santa Maria (UFSM) & 1 \\
\hline \multirow{2}{*}{ São Paulo } & Universidade Federal de Santa Catarina (UFSC) & 1 \\
\hline & Universidade Estadual Paulista (Unesp) & 1 \\
\cline { 2 - 4 } & Universidade Estadual de Campinas (Unicamp) & 12 \\
\cline { 2 - 4 } & Centro Universitário Fecap & 2 \\
\hline TOTAL & & \\
\hline
\end{tabular}

Das instituições universitárias que abrigam os grupos de pesquisa selecionados para análise dez são públicas (cinco estaduais e cinco federais) e duas, privadas. 
Alguns grupos de pesquisa em comunicação e esporte, com foco ou linha de pesquisa em comunicação, têm apenas um líder (cinco grupos) ou no máximo dois líderes (sete grupos) e essa característica não está associada à área predominante do conhecimento a que se filia o grupo.

Os grupos de pesquisa em comunicação e esporte são, em geral, relativamente novos, tendo mais de $40 \%$ deles três anos ou menos de formação. Apenas um deles está formado há mais de dez anos, conforme tabela 5.

Tabela 5

Grupos de pesquisa em comunicação e esporte: distribuição por ano de formação

\begin{tabular}{|c|c|c|}
\hline Ano de formação do grupo de pesquisa & Número de grupos de pesquisa & $\%$ \\
\hline 1998 & 1 & 8,33 \\
\hline 2003 & 1 & 8,33 \\
\hline 2004 & 2 & 16,66 \\
\hline 2005 & 2 & 16,66 \\
\hline 2007 & 1 & 8,33 \\
\hline 2008 & 3 & 25,00 \\
\hline 2009 & 1 & 8,33 \\
\hline 2010 & 1 & 8,33 \\
\hline TOTAL & 12 & 100,00 \\
\hline
\end{tabular}

\section{Pesquisadores por grupos de pesquisa}

Há diferenças importantes quando se considera o número total de pesquisadores que integram os distintos grupos de pesquisa. Alguns desses grupos abrigam um número significativo de pesquisadores, mas é possível identificar alguns problemas quando se contempla a relação direta desses pesquisadores com a temática envolvida ou mesmo o seu comprometimento com a pesquisa e produção. Muitos não apresentam produção alguma nos três anos considerados no levantamento (2009-2011) e outros não têm qualquer produção referente a essa temática. Certamente, contribuem para dar visibilidade ao grupo, mas não têm estado, ao longo de sua vida acadêmica, envolvidos diretamente com a comunicação e o esporte. Há grupos que apenas têm dois pesquisadores, incluído aí o próprio líder. A tabela 6 explicita o número total de pesquisadores por grupos de pesquisa. 
Tabela 6

Grupos de pesquisa em comunicação e esporte:

número de pesquisadores por grupo de pesquisa

\begin{tabular}{|l|c|c|}
\hline \multicolumn{1}{|c|}{ Número de pesquisadores } & Número de grupos de pesquisa & $\%$ \\
\hline 3 pesquisadores ou menos & 4 & 33,33 \\
\hline 4 ou 5 pesquisadores & 2 & 16,67 \\
\hline Entre 6 e 10 pesquisadores & 3 & 25,00 \\
\hline Mais de 10 pesquisadores & 3 & 25,00 \\
\hline & 12 & 100,00 \\
\hline
\end{tabular}

Os doze grupos são integrados por 82 pesquisadores em suas linhas especificas de comunicação e esporte. A maioria dos pesquisadores dessa temática, no Brasil, é constituída de homens (59 homens, ou seja, 71,95\% do total, contra 33 mulheres - 28,05\%), mas é interessante perceber que, sobretudo nos grupos com menor número de pesquisadores, há casos em que as mulheres prevalecem ou ocupam a função de líderes (elas são líderes em quatro grupos de pesquisa, ou seja em um terço deles). Em três grupos, as mulheres constituem a maioria e são líderes do grupo e em outro deles elas representam a totalidade dos pesquisadores. Em um grupo, o número de pesquisadores do gênero feminino e masculino se equivalem. Há pelo menos dois casos em que os pesquisadores são todos do gênero masculino.

\section{Formação básica dos pesquisadores}

No que diz respeito à formação básica dos pesquisadores (tabela 7), duas áreas são predominantes: educação física $(43,90 \%$ do total) e comunicação social $(15,85 \%$ do total), dado que está em sintonia com as especialidades de conhecimento a que se filiam os doze grupos de pesquisa com a temática de comunicação e esporte. É importante ressaltar, no entanto, que em muitos grupos a formação básica dos pesquisadores é eclética, com prevalência, excetuadas estas duas áreas predominantes, de formados em ciências humanas e sociais. Há um número significativo de pesquisadores (quase $10 \%$ do total) que têm formação em mais de uma área. Essas mesmas observações se repetem quando se examina a formação básica dos líderes dos grupos, conforme podemos perceber na tabela 8 . 
Tabela 7

Grupos de pesquisa em comunicação e esporte: formação básica dos pesquisadores

\begin{tabular}{|l|c|c|}
\hline \multicolumn{1}{|c|}{ Área de formação na graduação } & Número de pesquisadores & $\%$ \\
\hline Educação física & 36 & 43,90 \\
\hline Comunicação social & 13 & 15,85 \\
\hline Ciências Sociais / Sociologia & 5 & 6,10 \\
\hline História & 2 & 7,32 \\
\hline Letras & 2 & 2,44 \\
\hline Administração & 3 & 2.44 \\
\hline Economia & 1 & 3,65 \\
\hline Geografia & 1 & 1,22 \\
\hline Serviço social & 1 & 1,22 \\
\hline Ciências contábeis & 1 & 1,22 \\
\hline Artes plásticas & 1 & 1,22 \\
\hline Agronomia & 1 & 1,22 \\
\hline Engenharia civil & 1 & 1,22 \\
\hline Pesquisadores com mais de uma graduação & 1 & 9,76 \\
\hline Sem informação & 1,22 \\
\hline TotAL & 1 & 100,00 \\
\hline
\end{tabular}

Tabela 8

Grupos de pesquisa em comunicação e esporte: formação básica dos líderes dos grupos

\begin{tabular}{|l|c|c|}
\hline \multicolumn{1}{|c|}{ Área de formação na graduação } & Número de líderes & $\%$ \\
\hline Educação física & 9 & 52,94 \\
\hline Comunicação social & 2 & 11,77 \\
\hline Ciências Sociais / Sociologia & 2 & 11,77 \\
\hline Administração & 1 & 5,88 \\
\hline História & 1 & 5,88 \\
\hline Letras & 1 & 5,88 \\
\hline Formação em mais de uma graduação & 17 & 5,88 \\
\hline TOTAL & 17 & 100,00 \\
\hline
\end{tabular}


Em geral, os pesquisadores têm o mestrado como sua maior titulação, vindo a seguir o doutorado, o pós-doutorado e a especialização. Apenas dois pesquisadores listados nos grupos de pesquisa sob análise têm apenas graduação, como se pode depreender da tabela 9.

Tabela 9

Grupos de pesquisa em comunicação e esporte: maior titulação dos pesquisadores

\begin{tabular}{|l|c|c|}
\hline \multicolumn{1}{|c|}{ Maior titulação dos pesquisadores } & Número de pesquisadores & $\%$ \\
\hline Pós-doutorado & 6 & 7,32 \\
\hline Doutorado & 33 & 40,24 \\
\hline Mestrado & 34 & 41,46 \\
\hline Especialização & 5 & 6,10 \\
\hline Graduação & 3 & 3,66 \\
\hline Sem informação* & 1 & 1,22 \\
\hline TOTAL & 82 & 100,00 \\
\hline
\end{tabular}

* Um dos pesquisadores não tinha currículo Lattes ativo quando da realização do levantamento e, portanto, não foi possível resgatar a sua formação básica e sua titulação.

A maioria dos pesquisadores é titulada, prioritariamente, nesta ordem: educação física; comunicação social ou educação; ciências sociais/sociologia; administração ou antropologia; letras ou história.

Os líderes dos grupos têm como maior titulação o doutorado, vindo a seguir o pós-doutorado e o mestrado, como indica a tabela 10.

Tabela 10

Grupos de pesquisa em comunicação e esporte: maior titulação dos líderes

\begin{tabular}{|l|c|c|}
\hline \multicolumn{1}{|c|}{ Maior titulação dos líderes dos grupos } & Número de líderes & $\%$ \\
\hline Pós-doutorado & 3 & 17,65 \\
\hline Doutorado & 13 & 76,47 \\
\hline Mestrado & 1 & 5,88 \\
\hline TOTAL & 17 & 100,00 \\
\hline
\end{tabular}


Educação física/ ciências do esporte e comunicação social são as áreas de titulação da maioria dos líderes do grupo (seis cada), mas há também líderes de grupos formados em sociologia e antropologia.

\section{PRODUÇÃO BIBLIOGRÁFICA DOS GRUPOS}

A produção dos grupos, avaliada pela sua produção bibliográfica (basicamente constituída de livros, capítulos de livros, artigos em periódicos) nos anos 2009, 2010 e 2011 difere muitas vezes de maneira contundente de grupo para grupo. Assim, há grupos com elevada produção e outros com produção reduzidíssima. Um número significativo de pesquisadores não tem nenhuma produção ou com nenhuma produção na área específica de comunicação e esporte. Até líderes de grupos de pesquisa se incluem nessa situação, o que parece, de imediato, contraditório.

A produção dos grupos pode ser avaliada vista na tabela 11, com a indicação do grupo de pesquisa, sua respectiva produção total e média de produção por número de pesquisadores.

Tabela 11

Grupos de pesquisa em comunicação e esporte: produção bibliográfica dos grupos

\begin{tabular}{|c|c|c|}
\hline Grupos de pesquisa* & Produção bibliográfica total & $\begin{array}{c}\text { Média de produção por número } \\
\text { de pesquisadores }\end{array}$ \\
\hline 1 & 25 & 12,5 \\
\hline 2 & 3 & 1,0 \\
\hline 3 & 17 & 8,5 \\
\hline 4 & 46 & 7,7 \\
\hline 5 & 48 & 16 \\
\hline 6 & 24 & 4,8 \\
\hline 7 & 212 & 21,2 \\
\hline 8 & 98 & 7,0 \\
\hline 9 & 308 & 18,11 \\
\hline 10 & 31 & 15,5 \\
\hline 11 & 40 & 8,0 \\
\hline 12 & 16 & 1,33 \\
\hline MÉDIA & $\mathbf{8 6 8}$ & $\mathbf{1 0 , 5 9}$ \\
\hline
\end{tabular}

* Os números indicados nesta coluna correspondem aos grupos indicados no entretítulo "Relação dos grupos de pesquisa", na sequência deste texto 
É possível obter um número um pouco diferente, se considerarmos apenas a produção bibliográfica dos líderes de pesquisa. Em alguns casos, eles respondem por parcela expressiva da produção total dos grupos (a produção dos grupos 2 e 11, por exemplo, coincidem com a produção do grupo) e isso é mais evidente em grupos com menor número de pesquisadores, como se pode depreender da tabela 12 .

Tabela 12

Grupos de pesquisa em comunicação e esporte: produção bibliográfica dos líderes dos grupos

\begin{tabular}{|c|c|c|}
\hline Grupos de pesquisa & $\begin{array}{c}\text { Produção bibliográfica } \\
\text { do(s) líder(es) }\end{array}$ & $\begin{array}{c}\text { Média de produção por número } \\
\text { de pesquisadores }\end{array}$ \\
\hline 1 & 10 & 40,0 \\
\hline 2 & 3 & 100,0 \\
\hline 3 & 3 & 17,6 \\
\hline 4 & 32 & 69,6 \\
\hline 5 & 14 & 29,17 \\
\hline 6 & 18 & 75,0 \\
\hline 7 & 69 & 32,54 \\
\hline 8 & 29 & 29,6 \\
\hline 9 & 29 & 9,42 \\
\hline 10 & 31 & 100,0 \\
\hline 11 & 14 & 35,0 \\
\hline 12 & 3 & 18,7 \\
\hline MÉDIA & 255 & 15,0 \\
\hline
\end{tabular}

É fundamental atentar para o fato de que o total de produção bibliográfica, seja dos pesquisadores como um todo ou apenas dos líderes, não significa que ela é centrada na temática da comunicação e esporte. Muito pelo contrário, na maioria dos casos, ela chega a ser muito pequena, se a produção for considerada apenas em relação a esse foco específico. Além disso, é preciso lembrar que muitos pesquisadores não atualizam o seu currículo Lattes com a frequência desejada e que, por isso, em alguns casos, os dados referentes à produção podem estar desatualizados. 


\section{RELAÇÃO DOS GRUPOS DE PESQUISA}

Os doze grupos de pesquisa considerados estão listados a seguir, com a sua denominação, área predominante de conhecimento, ano de formação, vinculação com a unidade e a instituição, localização geográfica (município e estado), indicação do(s) líder(es) e as respectivas linhas de pesquisa, com destaque para a linha que contempla o foco específico sobre comunicação e esporte, quando o grupo incorpora duas ou mais linhas:

Grupo 1 - Bahia

Município: Ilhéus

Denominação: Grupo de estudos em representação social e mídia no esporte Gersom

Área de conhecimento predominante: Educação física

Ano de formação: 2008

Instituição: Universidade Estadual de Santa Cruz (Uesc)

Unidade: Colegiado de Educação Física / Departamento de Ciências da Saúde Líder: Márcia Morel

Linha de pesquisa: Representações sociais, midiáticas e esportivas da sociedade contemporânea

Número de pesquisadores: 2

Número de estudantes: 2

Número de técnicos: 0

Grupo 2 - Bahia

Município - Salvador

Denominação: Núcleo de estudos avançados em comunicação empresarial Nava

Área de conhecimento predominante: Comunicação

Ano de formação: 2004

Instituição: Universidade de Salvador (Unifacs)

Unidade: Mestrado em Administração

Líder: Vanessa Brasil Campos Rodriguez

Linhas de pesquisa: Comunicação, imagem e marketing; Estudo da imagem das organizações; Estudos avançados em semiótica e cultura

Linha de pesquisa que foca a temática comunicação e esporte: Comunicação, imagem e marketing

Número de pesquisadores: 6

Número de estudantes: 3

Número de técnicos: 0 
Grupo 3 - Espírito Santo

Município: Vitória

Denominação: Estudos de jornalismo brasileiro

Área de conhecimento predominante: Comunicação

Ano de formação: 2004

Instituição: Universidade Federal do Espírito Santo(Ufes)

Unidade: Departamento de Comunicação Social

Líder: Victor Israel Gentilli

Linhas de pesquisa: Critica da mídia; Índice da qualidade jornalística; Jorna-

lismo capixaba; Jornalismo e cidadania; Jornalismo especializado; Jornalismo,

narrativas e linguagens; Jornalismo segmentado; Teoria e ética do jornalismo.

Linha de pesquisa que foca a temática comunicação e esporte: Jornalismo especializado

Número de pesquisadores: 3

Número de estudantes: 12

Número de técnicos: 0

Grupo 4 - Goiás

Município: Goiânia

Denominação: Grupo de estudos e pesquisa em esporte, lazer e comunicação Área de conhecimento predominante: Educação física

Ano de formação: 2005

Instituição: Universidade Federal de Goiás (UFG)

Unidade: Faculdade de Educação Física

Líderes: Humberto Luis de Deus Inácio e Fernando Mascarenhas

Linhas de pesquisa: Educação física, comunicação e tecnologia; Lazer, cultura e educação; Políticas de esporte e lazer

Linha de pesquisa que foca a temática comunicação e esporte: Educação física, comunicação e tecnologia

Número de pesquisadores: 12

Número de estudantes: 17

Número de técnicos: 0

\section{Grupo 5 - Rio Grande do Sul}

Município: Santa Maria

Denominação: Comunicação e mídia na educação física e no esporte

Área de conhecimento predominante: Educação Física

Ano de Formação: 2007

Instituição: Universidade Federal de Santa Maria (UFSM)

Unidade: Laboratório de Pesquisa e Ensino do Movimento Humano; e Centro de Educação Física e Desportos 
Líder: Marli Hatje Hammes

Linhas de pesquisa: Comunicação e mídia na educação física escolar; Comunicação e mídia na saúde; Comunicação e mídia no esporte; Interdisciplinaridade na formação e atuação profissional em educação física

Linha de pesquisa que foca a temática comunicação e esporte: Comunicação e mídia no esporte

Número de pesquisadores: 5

Número de estudantes: 3

Número de técnicos: 0

Grupo 6 - Rio Grande do Sul

Município: Santa Maria

Denominação: Análise dos cenários esportivos na mídia

Área de conhecimento predominante: Educação física

Ano de formação: 2008

Instituição: Universidade Federal de Santa Maria (UFSM)

Unidade: Departamento de Desportos Coletivos

Líderes: Antonio Guilherme Schmitz Filho e Gilson Luiz Piber da Silva

Linhas de pesquisa: Ensino esportivo e navegação adaptativa; Estudo dos cená-

rios esportivos e futebolísticos; História e cultura esportiva; Mídia em processo (rádio, televisão, jornal e internet); Saúde midiatizada

Linha de pesquisa que foca a temática comunicação e esporte: Estudo dos cenários esportivos e futebolísticos

Número de pesquisadores: 9

Número de estudantes: 11

Número de técnicos: 0

Grupo 7 - Rio de Janeiro

Município: Rio de Janeiro

Denominação: Esporte e cultura

Área de conhecimento predominante: Comunicação

Ano de formação: 1998

Instituição: Universidade do Estado do Rio de Janeiro (Uerj)

Unidade: Departamento de Teoria da Comunicação

Líderes: Ronaldo George Helal e Hugo Rodolfo Lovisolo

Linha de pesquisa: Manifestações culturais do esporte moderno

Número de pesquisadores: 10

Número de estudantes: 7

Número de técnicos: 0 
Grupo 8 - Rio de Janeiro

Município: Rio de Janeiro

Denominação: Núcleo de estudos e pesquisas sobre esporte e sociedade - Nepess

Área de conhecimento predominante: Antropologia

Ano de formação: 2005

Instituição: Universidade Federal Fluminense (UFF)

Unidade: Curso de Mestrado em História

Líderes: Marcos Alvito Pereira de Souza e Luiz Fernando Rojo Mattos

Linhas de pesquisa: Esporte e sociedade

Número de pesquisadores: 14

Número de estudantes: 3

Número de técnicos: 0

\section{Grupo 9 - Santa Catarina}

Município: Florianópolis

Denominação: Laboratório e observatório da mídia esportiva

Área de conhecimento predominante: Educação física

Ano de formação: 2003

Instituição: Universidade Federal de Santa Catarina (UFSC)

Unidade: Departamento de Educação Física

Líderes: Giovani De Lorenzi Pires e Fernando Gonçalves Bitencourt

Linhas de pesquisa: Análises de produtos de mídia; Estudos dos meios e processos midiáticos; Mídia - Educação física

Linha de pesquisa que foca a temática comunicação e esporte: Análise de produtos de mídia

Número de pesquisadores: 17

Número de estudantes: 11

Número de técnicos: 0

\section{Grupo 10 - São Paulo}

Município: Campinas

Denominação: Comunicação e divulgação científica e cultural do esporte

Área de conhecimento predominante: Comunicação

Ano de formação: 2008

Instituição: Universidade Estadual de Campinas (Unicamp)

Unidade: Núcleo de Desenvolvimento da Criatividade

Líderes: Vera Regina Toledo Camargo e Maria Beatriz Rocha Ferreira

Linha de pesquisa: Comunicação e divulgação científica e cultural do esporte

Número de pesquisadores: 2

Número de estudantes: 8

Número de técnicos: 2 
Município: Bauru

Denominação: Grupo de estudos em comunicação esportiva e futebol - Gecef Área de conhecimento predominante: Comunicação

Ano de formação: 2010

Instituição: Universidade Estadual Paulista Júlio de Mesquita Filho (Unesp)

Unidade: Departamento de Ciências Humanas / Faculdade de Arquitetura Ar-

tes e Comunicação de Bauru

Líderes: José Carlos Marques e Marcos Américo

Linhas de pesquisa: Análise discursiva da comunicação esportiva; Antropologia, História e sociologia do esporte; Marketing e esporte.

Linha que foca a temática de comunicação e esporte: Análise discursiva da comunicação esportiva; Marketing e esporte

Número de pesquisadores: 8

Número de estudantes: 10

Número de técnicos:1

Grupo 12 - São Paulo

Município: São Paulo

Denominação: Comunicação e gestão do esporte

Área de conhecimento predominante: Comunicação

Ano de formação: 2009

Instituição: Fundação Escola de Comércio Armando Álvares Penteado (Fecap)

Unidade: Pró-Reitoria de Graduação

Líder: Ary José Rocco Júnior

Linhas de pesquisa: Comunicação e esporte; Gestão dos negócios do esporte Linha de pesquisa que foca a temática de comunicação e esporte: Comunicação e esporte

Número de pesquisadores: 12

Número de estudantes: 1

Número de técnicos: 0

\section{CONSIDERAÇÕES FINAIS}

O levantamento dos grupos de pesquisa sobre comunicação e esporte no Brasil evidenciou uma série de aspectos que devem merecer a atenção.

Em primeiro lugar, o total de grupos é pouco expressivo, particularmente se atentarmos para o fato de o esporte desempenhar papel importante no cenário nacional. Além disso, há uma discrepância significativa entre os grupos, com alguns deles apresentando uma produção global reduzida ou concentrada em um número pequeno de pesquisadores. Há também con- 
centração dos grupos em algumas regiões do país, com o Sul e o Sudeste respondendo por $75 \%$ deles.

Em segundo lugar, há grupos constituídos por poucos investigadores e este fato limita a produção, especialmente porque, no Brasil, eles acumulam inúmeras funções pedagógicas e administrativas e acabam por dedicar menos tempo às atividades de pesquisa. Ressalte-se ainda que há grupos que abrigam muitas linhas de pesquisa, não necessariamente focados nessa temática, diluindo a contribuição dos seus pesquisadores, o que compromete sensivelmente a produção específica em comunicação e esporte. Há também pesquisadores que integram os grupos sob análise e que não apresentam produção alguma, talvez porque não têm, em princípio, qualquer relação com a área.

Em terceiro lugar, é importante notar que os grupos de pesquisa, com raras exceções, não dispõem de espaços ou canais exclusivos (portais, blogs, periódicos etc.) para a divulgação de sua produção em comunicação e esporte. Assim, apenas excepcionalmente coordenam ou editam, a partir de seus pesquisadores ou mesmo de seus líderes, obras sobre comunicação e esporte em nosso país.

Provavelmente, o fato de existirem só poucos grupos de pesquisa voltados para a temática comunicação e esporte tenha a ver com a falta de prioridade com que a academia trate do tema, a ausência de disciplinas específicas nos cursos de graduação em comunicação e mesmo de linhas de pesquisa nos programas de pós-graduação em comunicação no Brasil.

\section{REFERÊNCIAS}

BARBERO, Heródoto; RANGEL, Patrícia. Manual do jornalismo esportivo. São Paulo: Comtexto, 2006.

CARDIA, Wesley. Marketing e patrocínio esportivo. Porto Alegre: Artmed, 2004.

COSTA, Lamartine da (Org). Atlas do esporte no Brasil. Rio de Janeiro: Shape, 2005.

COELHO, Paulo Vinicius. Jornalismo esportivo. São Paulo: Contexto, 2003.

DAMO, Arlei Sander. Futebol e identidade social: uma leitura antropológica das rivalidades entre torcedores e clubes. Porto Alegre: Editora da Universidade Federal do Rio Grande do Sul, 2002.

DAOLIO, Jocimar (Org). Futebol, cultura e sociedade. Campinas: Autores Associados, 2005.

ESTEVES, José. 0 desporto e as estruturas sociais. 3. ed. Lisboa: Prelo Editora, 1975.

GASTADO, Édison. Pátria, chuteiras e propaganda: o brasileiro na publicidade da Copa do Mundo. São Paulo: Annablume; São Leopoldo, RS:Ed. Unisinos, 2002.

GIULIANOTTI, Richard. Sociologia do futebol. São Paulo: Nova Alexandria, 2002.

GURGEL, Anderson. Futebol S/A: a economia em campo. São Paulo: Saraiva, 2006.

MAGNANE, Georges. Sociologia do esporte. São Paulo: Perspectiva, 1969.

MARQUES, José Carlos (Org). Comunicação e esporte: diálogos possíveis. São Paulo: Intercom, 2007.

MARQUES, José Carlos; CARVALHO, Sérgio; CAMARGO, Vera Regina T. Comunicação e esporte: tendências. Santa Maria, RS: Pallotti, 2005.

MORGAN, Melissa Johnson; SUMMERS, Jane. Marketing esportivo. São Paulo: Thompson Learning, 2008. 
MULLEN, Bernard; HARDY, Stephen; SUTTON, William A. Marketing esportivo. 2. ed. Porto Alegre: Artmed, 2004.

MYRA Y LOPES, E. e SILVA, Athayde Ribeiro da. Futebol e psicologia. Rio de Janeiro: Civilização Brasileira, 1964.

PITTS, Brenda G.; STOTLAR, David K. Fundamentos de marketing esportivo. São Paulo: Phorte, 2002.

REIN, Irving; KOTLA, Philip; SHIELDS, Ben. Marketing esportivo. Porto Alegre: Artmed, 2008.

RODRIGUES FILHO, Mário. 0 negro no futebol brasileiro. 4. ed. Rio de Janeiro: Mauad Editora / Faperj, 2003.

SILVA, Francisco Carlos Teixeira; SANTOS, Ricardo Pinto. Memória social dos esportes. Vol. 2. Futebol e política: a construção de uma identidade nacional. Rio de Janeiro: Mauad Editora; Faperp, 2006.

VILAS BOAS, Sérgio (Org). Formação e informação esportiva. São Paulo: Summus Editorial, 2005.

UNZELTTE, Celso. Jornalismo esportivo: relatos de uma paixão. São Paulo: Saraiva, 2009.

Recebido em: 02.09.2011 / Aceito em: 13.10.2011

66 OS GRUPOS DE PESQUISA EM COMUNICAÇÃO E ESPORTE NO BRASIL • WILSON DA COSTA BUENO 